Check for updates

Cite this: RSC Adv., 2018, 8, 14995

Received 28th February 2018

Accepted 10th April 2018

DOI: $10.1039 / \mathrm{c} 8 \mathrm{ra} 01786 \mathrm{~g}$

rsc.li/rsc-advances

\section{A sensitive fluorescent probe for alkaline phosphatase and an activity assay based on the aggregation-induced emission effect $\uparrow$}

\begin{abstract}
Wenjuan Zhang, Hanxiao Yang, Nan Li (iD) and Na Zhao (DD*
In this work, we report a fluorescent probe (TPEQN-P) for detecting alkaline phosphatase (ALP) with high sensitivity and monitoring its activity based on the specific aggregation-induced emission (AIE) effect. TPEQN-P can be constructed by conjugating the phosphate moiety into an AIE molecule (TPE-QI) through a reactive $p$-hydroxybenzyl group, which exhibits very weak emission in aqueous media due to its good water solubility. In the presence of ALP, TPEQN-P undergoes dephosphorylation and releases the hydrolysis product TPE-QI, which is intensely fluorescent because of its poor water solubility. The detection limit for ALP using TPEQN-P can be as low as $0.0077 \mathrm{U} \mathrm{L}^{-1}$ with a linear range of $0-30 \mathrm{mU}$ $\mathrm{mL}^{-1}$ in solution. TPEQN-P also shows excellent applicability in serum samples, demonstrating potential applications in clinical diagnosis and biomedical research. TPEQN-P also can be applied for the determination of ALP activity and in ALP inhibitor screening.
\end{abstract}

\section{Introduction}

Alkaline phosphatase (ALP), a crucial enzyme that exists in a variety of tissues (liver, bone, and so on), has been serving as a critical biomarker for molecular biology and as a diagnostic indicator for many human diseases, due to its great ability to remove the phosphate group from corresponding substrates (nucleic acids, proteins, alkaloids). ${ }^{1}$ For example, bone diseases (Paget's disease, osteoblastic bone cancer, and osteomalacia) and liver diseases or damage (hepatitis, cancer, and obstructive jaundice) are all correlated with an abnormal level of ALP in blood serum. ${ }^{2,3}$ Therefore, the establishment of a highly sensitive, highly selective, and rapid detection method for ALP is overwhelmingly meaningful.

Among the diverse detection strategies, fluorescence approaches have attracted considerable attention due to their high sensitivity, low cost, easy operation, and real-time detection. ${ }^{4}$ Numerous fluorescent probes for detecting ALP have been reported based on nanomaterials and small organic fluorophores with various mechanisms. ${ }^{5,6}$ Nevertheless, most of the traditional probes require either complex steps to give a sufficiently detectable signal, or the introduction of a quencher to reduce background fluorescence. Recently, a kind of fluorogen with aggregation-induced emission (AIE) characteristics has

Key Laboratory of Macromolecular Science of Shaanxi Province, Key Laboratory of Applied Surface and Colloid Chemistry of Ministry of Education, School of Chemistry \& Chemical Engineering, Shaanxi Normal University, Xi'an, 710119, China.E-mail:nzhao@snnu.edu.cn

$\dagger$ Electronic supplementary information (ESI) available: Synthesis, characterization and optical spectra. See DOI: 10.1039/c8ra01786g emerged as a promising fluorescent probe. Unlike conventional fluorophores, which suffer from emission quenching in high concentrations or in the solid state due to strong $\pi-\pi$ stacking, AIE fluorogens displayed no or weak emission in solution state, but had strong emission in their condensed state due to the restriction of intramolecular rotations (RIR). ${ }^{7}$ Taking advantage of this unique property, many fluorescent probes based on the AIE effect have been reported for the detection of ions, gases, small molecules, and biomolecules. ${ }^{8-11}$ In particular, this AIE feature has also been applied to detect ALP. ${ }^{12}$ Despite this great work, methods for the detection of ALP are still not sensitive enough. Thus, the development of a simple and sensitive AIE probe for ALP is still significantly important from both fundamental and practical viewpoints.

Herein, we designed and synthesized a cationic AIE fluorescent probe (TPEQN-P) bearing a phosphate moiety for detecting ALP. TPEQN-P has excellent water solubility and displayed negligible fluorescence in aqueous media. In the presence of ALP however, the fluorescence increased significantly due to TPEQN-P

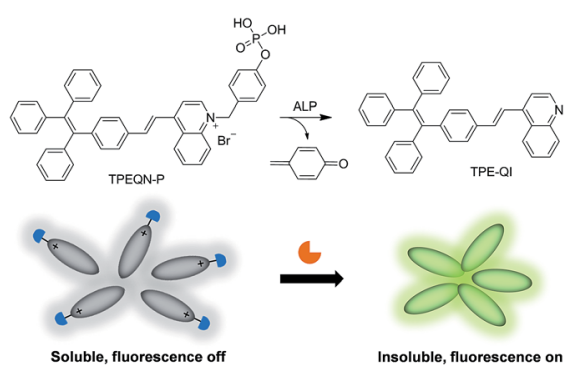

Scheme 1 Schematic illustration of the ALP detecting strategy. 
having undergone a dephosphorylation reaction that released the hydrolysis product (TPE-QI), which was insoluble and formed aggregates in the detecting media (Scheme 1). This specific fluorescence turn-on phenomenon enabled TPEQN-P to detect ALP with high sensitivity in solution as well as in a serum sample. The kinetic behaviour of ALP was determined and an ALP inhibitor screening was performed, with TPEQN-P.

\section{Results and discussion}

The synthetic route for TPEQN-P is shown in Scheme S1. $\dagger$ Briefly, intermediate compounds 1-4 and (E)-4-(4-(1,2,2-triphenylvinyl)styryl)quinoline (TPE-QI) were synthesized according to previous literature. ${ }^{\mathbf{1 3}, \mathbf{1 4}}$ TPE-QI and 4-(bromomethyl)phenyl diethyl phosphate (4) were refluxed in acetonitrile, followed by a hydrolysis reaction to give the desired product TPEQN-P in $79 \%$ yield. The chemical structures of these compounds were characterized by ${ }^{1} \mathrm{H}$ and ${ }^{13} \mathrm{C}$ NMR spectroscopy, high resolution mass spectrometry (HRMS), and satisfactory analysis data corresponding to their expected molecular structures were obtained.

TPEQN-P showed a long absorption band around $420 \mathrm{~nm}$ in DMSO solution (Fig. S1 $\dagger$ ), which was attributed to the typical intramolecular charge transfer (ICT) based on a previous report. ${ }^{14}$ Upon photoexcitation, TPEQN-P exhibited almost zero emission in solution (Fig. 1A). When the water fraction $\left(f_{\mathrm{w}}\right)$ was increased up to 50\%, TPEQN-P remained virtually nonfluorescent. However, when $f_{\mathrm{w}}$ was greater than $50 \%$, the fluorescence gradually increased. At a $f_{\mathrm{w}}$ of $90 \%$ the emission reached its maximum, which represented about a 10-fold enhancement in intensity than that obtained in pure DMSO (Fig. 1B). This enhanced emission could be associated with the formation of aggregates, which suppressed the non-radiative relaxation channels. For the purpose of practical application, the emission behaviour of TPEQN-P was also investigated in a DMSO and Tris-HCl buffer $(10 \mathrm{mM}, \mathrm{pH}=9.0)$ mixture. It is noted that the fluorescence intensity of TPEQN-P became weaker compared with that from the DMSO-water solution (Fig. S2 $\dagger$ ). Even when increasing the buffer fraction to $99 \%$, the
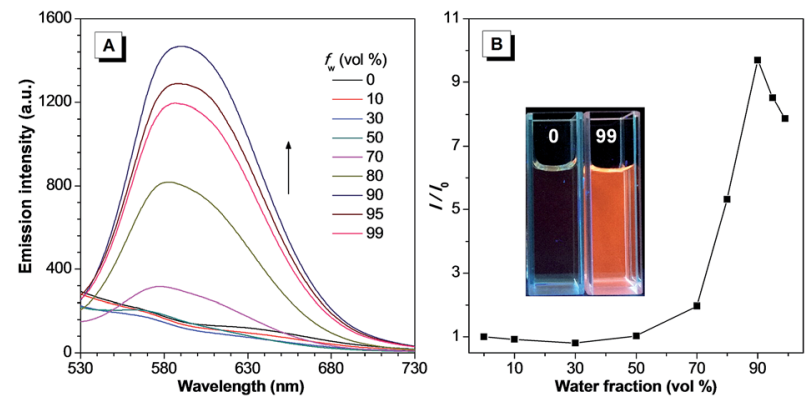

Fig. 1 (A) Emission spectra of TPEQN-P $(10 \mu \mathrm{M})$ in a DMSO/water mixture with different water fractions $\left(f_{\mathrm{w}}\right)$. (B) Plot of emission intensity at $590 \mathrm{~nm}$ versus the composition of the water mixtures of TPEQN-P, where $I_{0}$ is the emission intensity at $590 \mathrm{~nm}$ of TPEQN-P in pure DMSO solution. Inset: photograph of TPEQN-P in DMSO/water mixture with 0 and $99 \% f_{\mathrm{w}}$ under $365 \mathrm{~nm}$ irradiation. emission was still not strong, indicative of its better solubility in the buffer solution.

After proving the optical properties of TPEQN-P, its fluorescence response to ALP (100 $\left.\mathrm{mU} \mathrm{mL}^{-1}\right)$ was tested under different $\mathrm{pH}$ conditions (Fig. S3†). The results revealed that emission was enhanced for the $\mathrm{pH}$ values $8-10$, indicating that alkaline conditions were favourable for the detection process. Meanwhile, the effect of temperature for ALP detection (100 mU $\mathrm{mL}^{-1}$ ) was also investigated (Fig. S4†). It is obvious that the emission of TPEQN-P could be enhanced by ALP when the temperature was higher than $30{ }^{\circ} \mathrm{C}$. Combining the optical features and reactivity of TPEQN-P, we set up the optimized detection conditions as follows: the probe in $80 \%$ Tris- $\mathrm{HCl}$ buffer solution (10 mM, pH = 9.0) with $20 \%$ DMSO was incubated with ALP at $37^{\circ} \mathrm{C}$ for 1 hour.

The detailed response of TPEQN-P $(10 \mu \mathrm{M})$ towards ALP was then measured. As shown in Fig. 2A, after the addition of ALP (0-100 $\left.\mathrm{mU} \mathrm{mL}^{-1}\right)$ the absorption band at $430 \mathrm{~nm}$ decreased gradually, along with the increase of a new absorption peak at around $370 \mathrm{~nm}$. Meanwhile, a clear isosbestic point is present at $400 \mathrm{~nm}$, which suggests that a new species was generated by the reaction of TPEQN-P and ALP. Correspondingly, introducing ALP yielded an emission intensity enhancement at $495 \mathrm{~nm}$ (Fig. 2C). When $60 \mathrm{mU} \mathrm{mL} \mathrm{mL}^{-1}$ ALP was used the emission intensity reached saturation, with the emission color varying from originally colourless to green under $365 \mathrm{~nm}$ UV irradiation. It is noteworthy that the emission intensity at $495 \mathrm{~nm}$ exhibited a good linear relationship $\left(R^{2}=0.9923\right)$ against the concentration of ALP ranging from 0 to $30 \mathrm{mU} \mathrm{mL}^{-1}$ (Fig. 2D inset), which enabled TPEQN-P to serve as a probe for ALP with
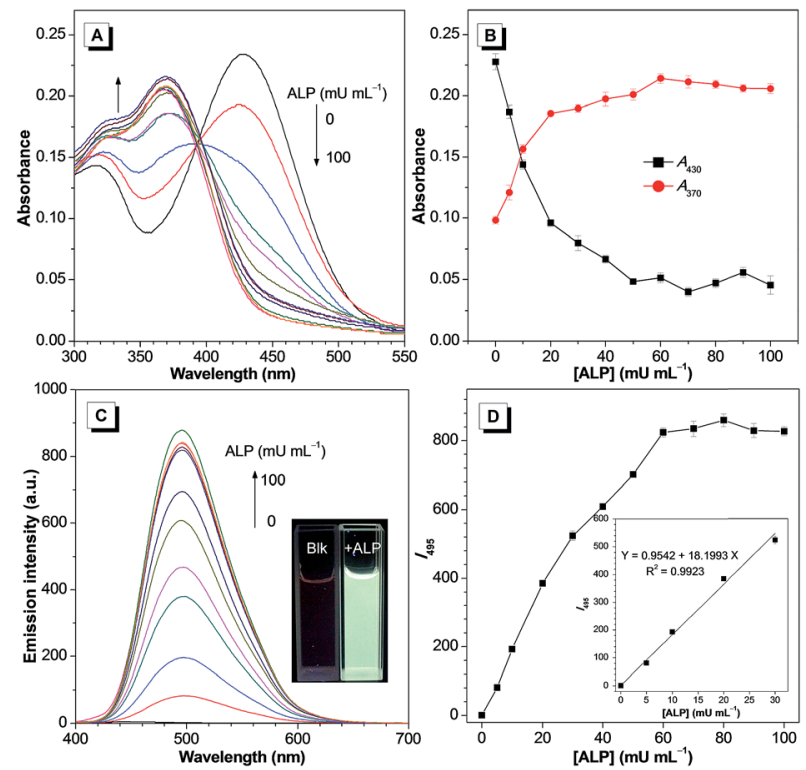

Fig. 2 (A) UV-vis and (C) emission spectra of TPEQN-P $(10 \mu M)$ after addition of ALP with different concentrations. Plots of (B) absorbance at $430 \mathrm{~nm}$ and $370 \mathrm{~nm}$ and (D) emission intensity at $495 \mathrm{~nm}$, vs. the concentration of ALP. Inset in (C): photograph of TPEQN-P in the absence and presence of ALP under $365 \mathrm{~nm}$ irradiation. Inset in (D): the linear relationship between intensity at $495 \mathrm{~nm}$ and the concentration of ALP $\left(0-30 \mathrm{mU} \mathrm{mL}^{-1}\right)$. 
the capability of quantitative analysis. The detection limit for ALP was calculated to be $0.0077 \mathrm{U} \mathrm{L}^{-1}$ based on the $3 \sigma / k$ method, which is much lower than those of most reported fluorescent probes (Table S1 $\dagger$ ), and is indicative of the high sensitivity of TPEQN-P.

To further explore the detecting capability of TPEQN-P in biological samples, an experiment was conducted in $80 \%$ Tris$\mathrm{HCl}$ buffer solution $(10 \mathrm{mM}, \mathrm{pH}=9.0)$ containing $2 \%$ fetal bovine serum (FBS). The fluorescence was also enhanced with increasing ALP concentration, although the rate of increase was slower than that under the media without FBS (Fig. S5 $\dagger$ ). Importantly, a good linear relationship $\left(R^{2}=0.9983\right)$ was also obtained when plotting the intensity at $495 \mathrm{~nm}$ against the concentration of ALP from 0 to $30 \mathrm{mU} \mathrm{mL}^{-1}$ (Fig. S5† inset). Accordingly, the standard addition method was used to analyse the concentration of ALP in diluted serum (Table 1). By increasing the concentration of the standard solutions of ALP from 5 to $25 \mathrm{mU} \mathrm{mL}{ }^{-1}$, the recovery of the spiked serum samples was more than $96 \%$ while the relative standard deviation (RSD) was less than 1.95\%, suggesting that TPEQN-P has a satisfying and practical applicability for the quantitative analysis of ALP in real samples.

In order to confirm that the fluorescence enhancement originated from the dephosphorylating reaction of TPEQN-P triggered by ALP, a high performance liquid chromatography (HPLC) analysis was performed. As described in Fig. S6, $\uparrow$ TPEQN-P displayed one peak at a retention time of $9.5 \mathrm{~min}$. After incubating TPEQN-P with ALP $\left(100 \mathrm{mU} \mathrm{mL}^{-1}\right)$ the signal at 9.5 min disappeared, while a new peak at 19.5 min appeared remarkably. Since pure TPE-QI was found to have a retention time of $19.5 \mathrm{~min}$, the observation proved that TPEQN-P was dephosphorylated efficiently by ALP and led to the generation of a new product TPE-QI. The effect of ALP on the micromorphology of TPEQN-P was further investigated by a scanning electron microscope (SEM) and the results revealed that TPEQN$P$ formed an amorphous film, probably due to its good solubility in aqueous solution (Fig. 3A). However, uniform nanoparticles were formed after the incubation of TPEQN-P with ALP (Fig. 3B), which implied that the hydrolysis product of TPE-QI possess poorer solubility under the same conditions. In addition, the average diameter of nanoaggregates in the presence of ALP was determined to be $280.8 \mathrm{~nm}$ by using dynamic light scattering (DLS), whereas no signal was detected for TPEQN-P alone (Fig. S7†), which further confirmed the formation of TPE-QI nanoaggregates in aqueous solution. Based on the RIR mechanism the aggregation blocks the intramolecular rotation, which results in an enhancement of fluorescence.

Table 1 Determination of ALP concentration in diluted serum samples

\begin{tabular}{lllll}
\hline Samples & $\begin{array}{l}\text { Added } \\
{\left[\mathrm{mU} \mathrm{mL}^{-1}\right]}\end{array}$ & $\begin{array}{l}\text { Found } \\
{\left[\mathrm{mU} \mathrm{mL}^{-1}\right]}\end{array}$ & $\begin{array}{l}\text { Recovery } \\
{[\%]}\end{array}$ & $\begin{array}{l}\text { RSD } \\
(n=3, \%)\end{array}$ \\
\hline \multirow{2}{*}{ Diluted serum } & 5 & 4.799 & 96.03 & 1.95 \\
& 15 & 14.858 & 99.07 & 1.76 \\
& 25 & 25.273 & 101.01 & 0.87
\end{tabular}

Fig. 3 SEM images of TPEQN-P $(10 \mu \mathrm{M})$ in the absence $(A)$ and in the presence (B) of ALP $\left(100 \mathrm{mU} \mathrm{mL}^{-1}\right)$.

Furthermore, dynamic studies were conducted to study the ALP-catalysed hydrolysis of TPEQN-P. The time-dependent fluorescence intensity increment was measured by using TPEQN-P $(10 \mu \mathrm{M})$ with different amounts of ALP ranging from 0 to $100 \mathrm{mU} \mathrm{mL} \mathrm{m}^{-1}$ within 80 minutes (Fig. S8†). Clearly, a sharper emission enhancement at $495 \mathrm{~nm}$ was acquired when high concentrations of ALP were loaded into the solution of TPEQN-P. This phenomenon demonstrated that a higher ALP concentration led to a faster cleavage reaction rate of TPEQN-P and promoted the generation of more TPE-QI.

Encouraged by the above results, kinetic parameters including the Michaelis constant $\left(K_{\mathrm{M}}\right)$, the turnover number $\left(k_{\mathrm{cat}}\right)$ and the catalytic efficiency constant $\left(k_{\text {cat }} / K_{\mathrm{M}}\right)$ were determined. Various concentrations of TPEQN-P $(0-15 \mu \mathrm{M})$ were incubated with ALP (50 $\mathrm{mU} \mathrm{mL}^{-1}$ ) and the change of intensity at $495 \mathrm{~nm}$ was monitored over 80 minutes. The emission intensity was found to be enhanced along with increase of TPEQN-P concentration, and this increase was rapid in the early stage (Fig. 4A). The data was then directly fitted to the Lineweaver-Burk plot, $1 / V_{0}=K_{\mathrm{M}} / k_{\mathrm{cat}}\left[\mathrm{E}_{0}\right]$ $[\mathrm{S}]+1 / k_{\text {cat }}\left[\mathrm{E}_{0}\right]$, where $V_{0}$ is the initial rate or velocity, $[\mathrm{S}]$ is the concentration of substrate and $\left[\mathrm{E}_{0}\right]$ is concentration of ALP. The slope and intercept were obtained from a straight line (Fig. 4B inset), and the $K_{\mathrm{M}}$ and $k_{\text {cat }}$ were determined to be $29 \mu \mathrm{M}$ and 4.95 $\mathrm{S}^{-1}$, respectively. The value of $k_{\text {cat }} / K_{\mathrm{M}}$ was calculated to be $5 \times 10^{5}$ $\mathrm{M}^{-1} \mathrm{~S}^{-1}$, which was higher than that of the commercial substrate 4-MUP $\left(k_{\text {cat }} / K_{\mathrm{M}}=7.7 \times 10^{3} \mathrm{M}^{-1} \mathrm{~S}^{-1}\right)$, suggesting the high catalytic efficiency of ALP towards TPEQN-P.

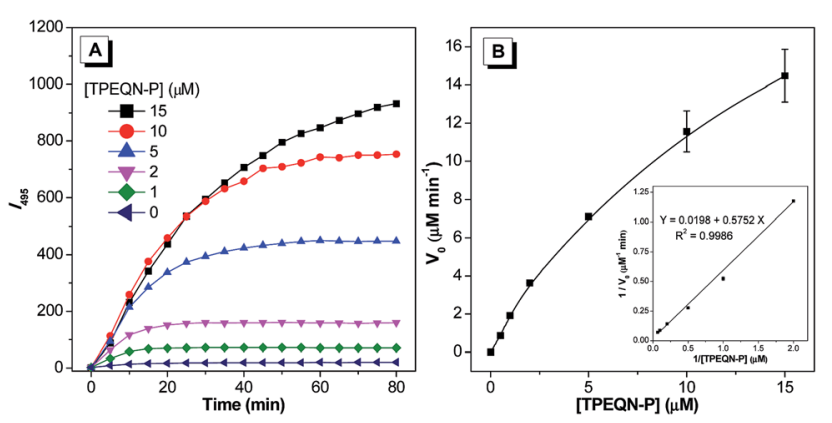

Fig. 4 (A) Time-dependent fluorescence intensity of TPEQN-P at different concentrations $(0-15 \mu \mathrm{M})$ incubated with $100 \mathrm{mU} \mathrm{mL} \mathrm{mL}^{-1} \mathrm{ALP}$ in aqueous solution. (B) Plot of initial velocity $\left(V_{0}\right)$ against TPEQN-P concentration. Inset in (B): Lineweaver-Burk plot for the reaction between TPEQN-P and ALP. 

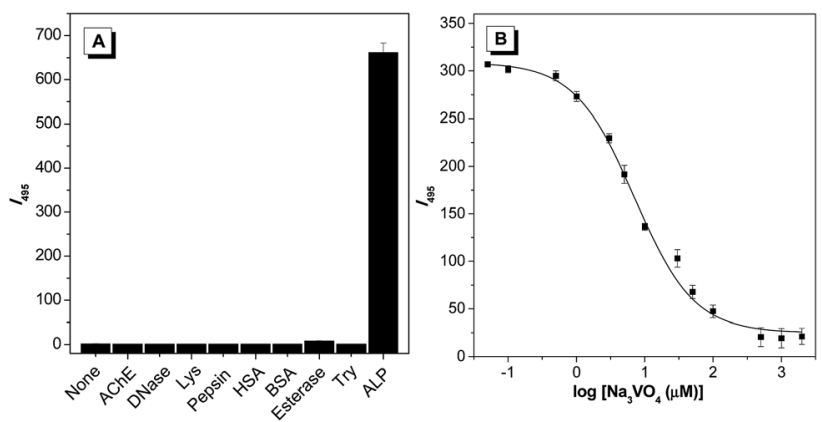

Fig. 5 (A) Bar graph of emission intensity at $495 \mathrm{~nm}$ of TPEQN-P (10 $\mu \mathrm{M}$ ) incubated with various proteins. (B) Relative activity of ALP (100 $\mathrm{mU} \mathrm{mL}^{-1}$ ) as a function of different concentrations of $\mathrm{Na}_{3} \mathrm{VO}_{4}$ in TPEQN-P solution $(10 \mu \mathrm{M})$.

In order to evaluate the selectivity of TPEQN-P experiments with other nonspecific enzymes including bovine serum albumin (BSA), deoxyribonuclease (DNase), acetylcholinesterase (AChE), esterase, human serum albumin (HSA), trypsin, pepsin, and lysozyme were performed under the same conditions. After incubation with $0.001 \mathrm{mg} \mathrm{mL}^{-1}$ of either BSA or HSA, or $100 \mathrm{mU} \mathrm{mL} \mathrm{m}^{-1}$ of one of the other enzymes, only ALP induced about a 650-fold enhancement of emission whereas the other proteins gave a negligible emission change (Fig. 5A and $\mathrm{S} 9 \dagger$ ). Experimental results indicated the existence of a specific reaction between TPEQN-P and ALP, which endows TPEQN-P with excellent selectivity towards ALP.

Considering that the activity of ALP can be extremely inhibited in the presence of an inhibitor, we also evaluated the possibility of using TPEQN-P for inhibitor screening assays. A common phosphatases inhibitor, sodium orthovanadate $\left(\mathrm{Na}_{3} \mathrm{VO}_{4}\right)$, was selected for this study. ALP was pre-incubated with different concentrations of $\mathrm{Na}_{3} \mathrm{VO}_{4}(0.01,0.05,0.1,0.5,1$, $3,5,10,30,50,100,500,1000$, and $2000 \mu \mathrm{M}$ ) for 30 minutes, then the above $\mathrm{Na}_{3} \mathrm{VO}_{4}$ pre-treated solution was added to a solution of TPEQN-P, and the enzymatic reaction was monitored by measuring the intensity at $495 \mathrm{~nm}$. As revealed in Fig. 5B, the emission intensity was reduced remarkably when the concentration of $\mathrm{Na}_{3} \mathrm{VO}_{4}$ was increased. The value of $\mathrm{IC}_{50}$ was calculated to be $8.124 \mu \mathrm{M}$ for $\mathrm{Na}_{3} \mathrm{VO}_{4}$, which was in good agreement with the values of previous reports. ${ }^{6 a, 13}$ These results confirmed that TPEQN-P could be used for both the detection of ALP activity and in a screening assay for an ALP inhibitor.

\section{Conclusions}

In conclusion, a sensitive fluorescent probe (TPEQN-P) was developed for detecting ALP as well as monitoring its activity based on the AIE effect. TPEQN-P was weakly emissive due to its great solubility in aqueous media. In the presence of ALP, TPEQN-P remarkably exhibited a fluorescence "turn-on" response because of the synergetic effect of ALP catalysis and the specific AIE feature of the catalysis product. The detection limit for ALP was as low as $0.0077 \mathrm{U} \mathrm{L}^{-1}$ with a linear range of 0 $30 \mathrm{mU} \mathrm{mL}{ }^{-1}$ in solution. Meanwhile, TPEQN-P also presented excellent applicability in a diluted serum sample. Furthermore, ALP activity determination and ALP inhibitor screening could be successfully investigated using TPEQN-P.

\section{Experimental section}

\section{Chemical}

$\mathrm{CH}_{2} \mathrm{Cl}_{2}$ and $\mathrm{N}, \mathrm{N}$-dimethylformamide (DMF) were distilled over $\mathrm{CaH}_{2}$. All other reagents and solvents were used directly from the corresponding supplier without further purification. All starting materials were purchased from TCI, Aladdin, Energy, Accela and used directly. Bovine serum albumin (BSA) and esterase were purchased from Aladdin, deoxyribonuclease (DNase), acetylcholinesterase (AChE), human serum albumin (HSA), trypsin, pepsin and lysozyme were purchased from Sigma.

\section{Instrumentation}

Nuclear magnetic resonance spectra $\left({ }^{1} \mathrm{H},{ }^{13} \mathrm{C}\right.$ NMR $)$ were recorded on a Bruker Ascend $400\left({ }^{1} \mathrm{H}\right.$ at $400 \mathrm{MHz},{ }^{13} \mathrm{C}$ at 101 $\mathrm{MHz})$ or a Bruker Ascend $600\left({ }^{1} \mathrm{H}\right.$ at $600 \mathrm{MHz},{ }^{13} \mathrm{C}$ at $\left.151 \mathrm{MHz}\right)$. The chemical shifts are reported as ppm and solvent residual peaks were shown as follows: $\mathrm{CDCl}_{3} \delta \mathrm{H}(7.26 \mathrm{ppm})$ and $\delta \mathrm{C}$ (77.16 ppm); $\mathrm{CD}_{3} \mathrm{OH} \delta \mathrm{H}(3.31 \mathrm{ppm})$ and $\delta \mathrm{C}$ (49.00 ppm). UVvisible absorption spectra were measured on a Purkinje TU1950 spectrometer. Fluorescence spectra were recorded on a Hitachi F-7000 spectrometer. Dynamic Light Scattering (DLS) was carried out on a Malvern Zetasizer Nano ZS90. High performance liquid chromatography (HPLC) spectra were obtained on a Hitachi Chromaster. SEM pictures were be obtained on an environmental scanning electron microscope Quanta 200. High-resolution mass spectra were obtained on a Bruker Maxis and Microflex and are reported as $m / z$ (relative intensity).

\section{Preparation of aggregates}

Stock DMSO solutions of the fluorogens with a concentration of $1 \mathrm{mM}$ were prepared. Aliquots of the stock solutions were transferred to $3 \mathrm{~mL}$ volumetric flasks. After appropriate amounts of DMSO were added, water was added dropwise under vigorous stirring to give $10 \mu \mathrm{M}$ solutions with different water contents (0-99 vol\%). The fluorescence measurements of the resulting solutions were then performed immediately.

\section{ALP activity assay}

TPEQN-P stock solution ( $1 \mathrm{mM}$ in DMSO) was diluted with $80 \%$ Tris-HCl buffer $(10 \mathrm{mM}, \mathrm{pH}=9.0)$ and 20\% DMSO to make a 10 $\mu \mathrm{M}$ working solution. Different amounts of ALP stock solutions (75 $\mathrm{U} \mathrm{mL}^{-1}$ in Tris-HCl buffer, $10 \mathrm{mM}$, pH 9.0, $1 \mathrm{mM} \mathrm{MgCl}_{2}$, $0.1 \mathrm{mM} \mathrm{ZnCl}_{2}$ ) were added into the solution of TPEQN-P to yield final concentrations of ALP ranging from 0 to $100 \mathrm{mU} \mathrm{mL} \mathrm{m}^{-1}$. The UV-vis and fluorescence measurements were carried out after the prepared solutions were incubated at $37^{\circ} \mathrm{C}$ for 1 hour. For the selectivity test, all other enzymes were tested under the same conditions with ALP. 


\section{ALP activity assay in serum samples}

The fetal bovine serum (FBS) was diluted with Tris-HCl buffer $(10 \mathrm{mM}, \mathrm{pH}=9.0)$ to prepare $80 \%$ Tris-HCl buffer $(10 \mathrm{mM}$, $\mathrm{pH}=9.0$ ) and $20 \%$ DMSO (containing $2 \%$ FBS) solution. The ALP activity assay of the serum sample was then carried out according to above method "ALP Activity Assay". Different concentrations of $\operatorname{ALP}\left(5,15\right.$ and $\left.25 \mathrm{mU} \mathrm{mL}^{-1}\right)$ were spiked with the serum solution and used for recovery tests.

\section{Kinetic studies}

To determine the kinetic parameters of the hydrolysis reaction by ALP, TPEQN-P was dissolved in $80 \%$ Tris-HCl buffer $(10 \mathrm{mM}$, $\mathrm{pH}=9.0$ ) and $20 \%$ DMSO to prepare TPEQN-P solutions of different concentrations $(0,1.0,2.0,5.0$ and $10 \mu \mathrm{M})$, followed by the addition of ALP $\left(100 \mathrm{mU} \mathrm{mL}^{-1}\right)$ for the dephosphorylation reaction. The enzymatic reaction was monitored through the change of fluorescence intensity at $495 \mathrm{~nm}$ at different time intervals after incubation at $37{ }^{\circ} \mathrm{C}$ for 1 hour. The kinetic parameters (e.g., $K_{\mathrm{M}}$ and $k_{\text {cat }}$ ) of the hydrolysis reaction of TPEQN-P were determined from a Lineweaver-Burke plot.

\section{ALP inhibitor investigation}

In order to investigate the application of TPEQN-P for ALP inhibitor evaluation, $\mathrm{Na}_{3} \mathrm{VO}_{4}$ solution with different concentrations (from 0.01 to $2000 \mu \mathrm{M}$ ) was added into the ALP reaction system $\left(100 \mathrm{mU} \mathrm{mL}{ }^{-1}\right)$ at $37^{\circ} \mathrm{C}$ for $30 \mathrm{~min}$. The inhibitor treated ALP reaction solution was mixed with TPEQN-P $(10 \mu \mathrm{M})$ in $80 \%$ Tris-HCl buffer $(10 \mathrm{mM}, \mathrm{pH}=9.0)$ and $20 \% \mathrm{DMSO}$ at $37^{\circ} \mathrm{C}$ for 1 hour, and then the fluorescence spectrum was recorded.

\section{Conflicts of interest}

The authors declare that there are no conflicts of interest.

\section{Acknowledgements}

We are grateful for financial support from the National Natural Science Foundation of China (51403122, 21672135 and 21402115), the Fundamental Research Funds for the Central Universities (GK201703024 and GK201702002), the Young Talent Fund of University Association for Science and Technology in Shaanxi (2017030021) and the Natural Science Foundation of Shaanxi Province (2016JQ2020).

\section{Notes and references}

1 (a) J. E. Coleman, Annu. Rev. Biophys. Biomol. Struct., 1992, 21, 441-483; (b) N. J. Fermandez and B. A. Kidney, Vet. Clin. Pathol., 2007, 36, 223-227.

2 (a) O. Maldonado, R. Demasi, Y. Maldonado, M. Taylor, F. Troncale and R. Vender, J. Clin. Gastroenterol., 1998, 27, 342-345; (b) A. R. Khan, F. R. Awan, S. Najam, M. Islam, T. Siddique and M. Zain, JPMA, J. Pak. Med. Assoc., 2015, 65, 1182-1185.

3 (a) J. P. Smus, C. C. Moura, E. McMorrow, R. S. Tare, R. O. C. Oreffo and S. Mahajan, Chem. Sci., 2015, 6, 7089-
7096; (b) K. Ooi, K. Shiraki, Y. Morishita and T. Nobori, J. Clin. Lab. Anal., 2007, 21, 133-139.

4 (a) Y. Yang, Q. Zhao, W. Feng and F. Li, Chem. Rev., 2013, 113, 192-270; (b) W. Sun, S. Guo, C. Hu, J. Fan and X. Peng, Chem. Rev., 2016, 116, 7768-7817; (c) T. D. Ashton, K. A. Jolliffe and F. M. Feffer, Chem. Soc. Rev., 2015, 44, 4547-4595; (d) L. You, D. Zha and E. V. Anslyn, Chem. Rev., 2015, 115, 7840-7892; (e) M. Vendrell, D. Zhai, J. C. Er and Y. T. Chang, Chem. Rev., 2012, 112, 4391-4420; (f) J. L. Kolanowski, F. Liu and E. J. New, Chem. Soc. Rev., 2018, 47, 195-208; $(g)$ A. S. Klymchenko, Acc. Chem. Res., 2017, 50, 366-375; $(h)$ S. Leng, Q. L. Qiao, Y. Gao, L. Miao, W. G. Deng and Z. C. Xu, Chin. Chem. Lett., 2017, 28, 1911-1915.

5 (a) J. J. Liu, D. S. Tang, Z. T. Chen, X. M. Yan, Z. Zhong, L. T. Kang and Z. N. Yao, Biosens. Bioelectron., 2017, 94, 271-277; (b) Z. S. Qian, L. J. Chai, C. Tang, Y. Y. Huang, J. R. Chen and H. Feng, Anal. Chem., 2015, 87, 2966-2973; (c) H. Liu, M. Li, Y. Xia and X. Ren, ACS Appl. Mater. Interfaces, 2017, 9, 120-126; (d) R. Freeman, T. Finder, R. Gill and I. Willner, Nano Lett., 2010, 10, 2192-2196; (e) P. Song, Q. Liu, Y. Zhang, W. Liu, M. Meng, Y. Yin and R. Xi, RSC Adv., 2018, 8, 162-169.

6 (a) Y. Tan, L. Zhang, K. H. Man, R. Peltier, G. Chen, H. Zhang, L. Zhou, F. Wang, D. Ho, S. Q. Yao, Y. Hu and H. Sun, ACS Appl. Mater. Interfaces, 2017, 9, 6796-6803; (b) M. C. L. Yeung and V. W. W. Yam, Chem. Sci., 2013, 4, 2928-2935; (c) L. Jia, J. P. Xu, D. Li, S. P. Pang, Y. Fang, Z. G. Song and J. Ji, Chem. Commun., 2010, 46, 7166-7168; (d) Q. Chen, N. Bian, C. Cao, X. L. Qiu, A. D. Qi and B. H. Han, Chem. Commun., 2010, 46, 4067-4069; (e) T. I. Kim, H. Kim, Y. Choi and Y. Kim, Chem. Commun., 2011, 47, 9825-9827; (f) L. Zhang, J. Zhao, M. Duan, H. Zhang, J. Jiang and R. Yu, Anal. Chem., 2013, 85, 37973801.

7 (a) J. Luo, Z. Xie, J. W. Y. Lam, L. Cheng, H. Chen, C. Qiu, H. S. Kwok, X. Zhan, Y. Liu, D. Zhu and B. Z. Tang, Chem. Commun., 2001, 1740-1741; (b) J. Mei, N. L. C. Leung, R. T. K. Kwok, J. W. Y. Lam and B. Z. Tang, Chem. Rev., 2015, 115, 11718-11940; (c) D. Ding, K. Li, B. Liu and B. Z. Tang, Acc. Chem. Res., 2013, 46, 2441-2453; (d) Y. Hong, J. W. Y. Lam and B. Z. Tang, Chem. Soc. Rev., 2011, 40, 5361-5388; (e) Z. Zhao, B. He and B. Z. Tang, Chem. Sci., 2015, 6, 5347-5365; (f) G. Zhang, F. Hu and D. Zhang, Langmuir, 2015, 31, 4593-4604.

8 (a) P. Alam, G. Kaur, C. Climent, S. Pasha, D. Casanova, P. Alemany, A. Roy Choudhury and I. R. Laskar, Dalton Trans., 2014, 43, 16431-16440; (b) L. N. Neupane, E. T. Oh, H. J. Park and K. H. Lee, Anal. Chem., 2016, 88, 3333-3340; (c) C. Niu, Q. Liu, Z. Shang, L. Zhao and J. Ouyang, Nanoscale, 2015, 7, 8457-8465; (d) N. Zhao, J. W. Y. Lam, H. H. Y. Sung, H. M. Su, I. D. Williams, K. S. Wong and B. Z. Tang, Chem.-Eur. J., 2014, 20, 133-138; (e) Y. Zhang, Y. Li, X. Yang, Y. Ding, Z. Zhao, X. Liu, Z. Yang and Y. Cui, Talanta, 2018, 179, 177-185; ( $f$ ) A. Chatterjee, M. Banerjee, D. G. Khandare, R. U. Gawas, S. C. Mascarenhas, A. Ganguly, R. Gupta and H. Joshi, Anal. Chem., 2017, 89, 
12698-12704; (g) J. Wang, Y. Li, K. Li, X. Meng and H. Hou, Chem.-Eur. J., 2017, 23, 5081-5089.

9 (a) Y. Hang, J. Wang, T. Jiang, N. Lu and J. Hua, Anal. Chem., 2016, 88, 1696-1703; (b) S. Samanta, U. Manna, T. Ray and G. Das, Dalton Trans., 2015, 44, 18902-18910; (c) C. Gao, G. Gao, J. Lan and J. You, Chem. Commun., 2014, 50, 56235625; (d) J. Zhao, D. Yang, Y. X. Zhao, X. J. Yang, Y. Y. Wang and B. Wu, Angew. Chem., Int. Ed., 2014, 53, 6632-6636; (e) H. R. Xu, K. Li, S. Y. Jiao, L. L. Li, S. L. Pan and X. Q. Yu, Chin. J. Chem., 2015, 26, 877-880; $(f)$ S. Y. Chen and X. L. Ni, RSC Adv., 2016, 6, 6997-7001; $(g)$ Y. Hang, J. Wang, T. Jiang, N. Lu and J. Hua, Anal. Chem., 2016, 88, 1696-1703.

10 (a) X. Wang, J. Hu, G. Zhang and S. Liu, J. Am. Chem. Soc., 2014, 136, 9890-9893; (b) Y. Zhuang, F. Huang, Q. Xu, M. Zhang, X. Lou and F. Xia, Anal. Chem., 2016, 88, 32893294; (c) Y. Wang, X. Wu, Y. Cheng and X. Zhao, Chem. Commun., 2016, 52, 3478-3481; (d) W. Shen, J. Yu, J. Ge, R. Zhang, F. Cheng, X. Li, Y. Fan, S. Yu, B. Liu and Q. Zhu, ACS Appl. Mater. Interfaces, 2016, 8, 927-935; (e) X. T. Chen, Y. Xiang, N. Li, P. S. Song and A. J. Tong, Analyst, 2010, 135, 1098-1105; (f) X. Xu, J. Huang, J. Li, J. Yan, J. Qin and Z. Li, Chem. Commun., 2011, 47, 1238512387.
11 (a) M. Gao, S. Li, Y. Lin, Y. Geng, X. Ling, L. Wang, A. Qin and B. Z. Tang, ACS Sens., 2016, 1, 179-184; (b) Y. Liu, Y. H. Tang, N. N. Barashkov, I. S. Irgibaeva, J. W. Y. Lam, R. R. Hu, D. Birimzhanova, Y. Yu and B. Z. Tang, J. Am. Chem. Soc., 2010, 132, 13951-13953; (c) S. Gong, Q. Liu, X. Wang, B. Xia, Z. Liu and W. He, Dalton Trans., 2015, 44, 1406314070; (d) H. Xie, Y. Wu, F. Zeng, J. Chen and S. Wu, Chem. Commun., 2017, 53, 9813-9816; (e) Z. Wang, H. Nie, Z. Yu, A. Qin, Z. Zhao and B. Z. Tang, J. Mater. Chem. C, 2015, 3, 9103-9111.

12 (a) Z. G. Song, T. K. Kwok Ryan, E. Zhao, Z. K. He, Y. N. Hong, W. Y. Lam Jacky, B. Liu and B. Z. Tang, ACS Appl. Mater. Interfaces, 2014, 6, 17245-17254; (b) J. Liang, T. K. K. Ryan, H. Shi, B. Z. Tang and B. Liu, ACS Appl. Mater. Interfaces, 2013, 5, 8784-8789; (c) F. Y. Cao, Y. Long, S. B. Wang, B. Li, J. X. Fan, X. Zeng and X. Z. Zhang, J. Mater. Chem. B, 2016, 4, 4534-4541; (d) X. Gu, G. Zhang, Z. Wang, W. Liu, L. Xiao and D. Zhang, Analyst, 2013, 138, 2427-2431; (e) J. Shi, Y. Li, Q. Li and Z. Li, ACS Appl. Mater. Interfaces, 2018, 10, 12278-12294.

13 H. Zhang, C. Xu, J. Liu, X. Li, L. Guo and X. Li, Chem. Commun., 2015, 51, 7031-7034.

14 R. X. Zhang, P. F. Li, W. J. Zhang, N. Li and N. Zhao, J. Mater. Chem. C, 2016, 4, 10479-10485. 